Pacheco, C. (2016). Impacto económico de la violencia armada sobre la producción campesina, caso municipios zona de distensión departamento del Meta, Colombia (1991-2014). Revista Lebret, 8. Bucaramanga, Colombia: Universidad Santo Tomás, pp. 93 - 123. ISSN: $2145-5996$

\title{
Impacto económico de la violencia armada sobre la producción campesina, caso municipios zona de distensión departamento del Meta, Colombia (1991-2014)*
}

\section{Economic impact of armed violence in rural production case municipalities of relaxation area Department Meta, Colombia (1991-2014)}

Camilo Ernesto Pacheco Pérez

\begin{abstract}
Resumen
En el documento se analizan los impactos económicos de la violencia armada sobre la producción campesina, caso municipios zona de distensión departamento del Meta, Colombia (1991-2014). Para ello se adelantó una recolección de datos de producción agrícola familiar campesina, tasas de desplazamiento, homicidios, masacres y secuestros efectuados en el marco del conflicto armado en los municipios objeto de este estudio. Datos que constituyeron la base para la formulación de un modelo econométrico sustentado en la teoría neoclásica de la economía campesina y la teoría sociológica liberal del conflicto armado; lo que permitió consolidar un análisis moderno de la economía campesina colombiana en el siglo XXI. Definitivamente el conflicto armado se presenta como un factor determinante en el desarrollo de la producción agrícola familiar campesina en los municipios del suroccidente del departamento del Meta, toda vez que dicho territorio ha albergado históricamente grupos al margen de la ley, que sumados a una escasa presencia estatal mantienen dinámicas propias del conflicto (desplazamiento, masacres, secuestros y homicidios), exacerbadas en el período 2012-2010, posterior al fracaso del tratado de paz del presidente Pastrana; las cuales son susceptibles de ser abordadas a través de la lectura de este estudio.
\end{abstract}

Palabras clave

Conflicto armado, zona de distensión, producción familiar campesina

Códigos de clasificación JEL: Q15, R11, R14, R21, R22

\begin{abstract}
In the paper, the effects of the armed conflict generated in the rural family productive activity in the municipalities of the demilitarized zone in the department of Meta in the period 1991-2014 are analyzed. This requires a data collection rural family farm production, displacement rates, homicides, massacres and kidnappings carried out in the context of the armed conflict in the municipalities object of this study was ahead. Data that formed the basis for the formulation of an econometric model based on the neoclassical theory of the peasant economy and the liberal sociological theory of armed conflict; which allowed to consolidate a modern analysis of Colombian peasant economy in the twenty-first century. Definitely the armed conflict is presented as a determining factor in the development of the rural family farm production in the municipalities of southwestern department of Meta, since that territory has historically housed, groups outside the law, which added to a limited state presence maintained own dynamics of the conflict (displacement, massacres, kidnappings and killings), which are likely to be addressed through reading this study.
\end{abstract}

\section{Keywords}

Armed conflict, distention zone, peasant family production.

* Artículo derivado del proyecto "Efectos del conflicto armado sobre la oferta agrícola campesina, en los municipios del suroccidente departamento del Meta (1991-2014), en el marco de la maestría en Administración Universidad Santo Tomás.

1 Magíster en Ciencias Económicas. Docente investigador Universidad Cooperativa de Colombia sede Villavicencio. Correo electrónico: camilo.pacheco@campusucc.edu.co 


\section{Introducción}

El departamento del Meta desde un punto de vista histórico, tiene una vocación agropecuaria asociada generalmente con ganadería y monocultivos. Sin embargo, la agricultura familiar campesina (economía campesina) como forma de producción en el campo, también es un aportante a la economía y desarrollo rural.

De hecho, la economía campesina que tiene una lógica distinta a la economía agropecuaria, presenta un escenario heterogéneo (cultura y prácticas productivas alrededor de policultivos), y al igual que otros tipos de actividades económicas ha sido impactada por hechos de violencia.

Por tal motivo, analizar la relación entre la producción familiar campesina y el conflicto armado, resulta necesario y pertinente en un marco de posconflicto. Lo anterior, dado que la búsqueda de estrategias sociopolíticas para el sector campesino requiere de indicadores que faciliten el diseño de políticas públicas favorables al desarrollo y crecimiento económico de las comunidades en sus respectivos territorios.

Bajo este marco, es importante destacar la declaración del 2014 como Año Internacional de la Agricultura Familiar, por parte de los delegados de las organizaciones campesinas, indígenas, montubios, mujeres, organismos no gubernamentales y representantes del Estado, que se reunieron en Quito 2013, en el marco de la Comunidad de Estados Latinoamericanos y el Caribe (CELAC), para discutir en torno a la necesidad de fortalecer "el diálogo y la cooperación sobre desarrollo territorial rural y la agricultura familiar, campesina e indígena, a partir de las iniciativas emprendidas por los Estados miembros, entre ellas la Iniciativa de América Latina y el Caribe sin Hambre 2025 y la Reunión Especializada sobre Agricultura Familiar (REAF)" (Celac, 2013).

En efecto, al verificar la literatura en el marco de la economía del campesino, se encuentra que esta tiene una tendencia filosófica no cuantitativa, que permita desideologizar el discurso y orientarlo hacia la práctica, pues de acuerdo con los esfuerzos realizados a nivel internacional se tiene según un estudio de la FAO/BID (2008), que más del $60 \%$ de las unidades familiares corresponderían a la categoría de subsistencia y solo cerca de un $12 \%$ serían consideradas unidades consolidadas o excedentarias, mientras el resto se sitúa en una etapa intermedia o transicional, donde las variables exógenas y diversas las llevarían a ascender o a descender (Schejtman, 2008).

En lo que respecta al nivel local y específicamente a la capital del departamento del Meta, se han desarrollado una serie de estudios de caracterización social, productiva y cultural de la familia campesina (Pacheco \& Vidales, 2012) que permiten comparar sus resultados con los obtenidos en la FAO y el BID, al respecto.

Desde el punto de vista del conflicto armado, aproximarse a la relación histórica de este con la producción del sector rural y en concreto con la oferta familiar 
campesina, resulta de gran importancia para el análisis del conflicto y violencia en las regiones, como también en los estudios de desarrollo rural en el país.

\section{Aspectos teóricos y metodológicos}

Tipo de investigación: la investigación es cuali-cuantitativa según relación del problema y los objetivos definidos.

Partiendo de la teorización de la economía campesina (teoría neoclásica de la economía campesina) (Shultz, 1964) y el conflicto armado (teoría liberal sociológica del conflicto) (García, 2008), así como la contextualización académica, político, social, territorial y económica, se presentan comparativamente las diferentes tendencias que el conflicto armado mantiene con la oferta familiar campesina, en cinco municipios del departamento del Meta, determinando su relación y posterior estimación del impacto económico generado entre los años 1991 y 2014. De esta manera la región de estudio está limitada por los municipios de Mesetas, Vistahermosa, San Juan de Arama, La Uribe y La Macarena, los cuales hicieron parte de la zona de distensión en los años 1998-2012.

Ahora bien, teniendo en cuenta que el departamento del Meta tiene una vocación fuerte en producción de materias primas, especialmente la de alimentos y con una alta heterogeneidad productiva en términos de cantidad y tipo de productos ofertados; -debido a su condición geográfica, poblacional y cultural- se establecieron criterios adecuados en torno a la producción de alimentos y su economía, con el objeto de identificar plenamente las variables (productos) que hacen parte de la "economía familiar campesina" y no de la "economía agropecuaria", la cual y como lo hemos anotado, no tienen la misma lógica.

\section{Criterios y supuestos}

- Los productos, son cultivados y cosechados en los cinco municipios de estudio sin excepción.

- Los productos, culturalmente hacen parte de policultivos familiares y no monocultivos.

- Las áreas sembradas y cosechadas son pequeñas (2 Ha - $20 \mathrm{Ha})$.

- En la producción se involucra la mayor parte de la familia (se estableció a través de visita de campo).

Teniendo en cuenta lo anterior, el departamento del Meta produce café, caña azucarera, plátano, caña panelera, maíz tradicional, yuca, frijol, maíz tecnificado, arroz riego, cacao, piña, papa criolla, ají, palma de aceite, naranja, aguacate, arroz secado manual, cacao, mango, mora, lulo, arveja, habichuela, tomate invernadero, ahuyama, tomate de árbol, cítricos, patilla, guayaba pera, maracuyá, papaya, 
guanábana, cebolla de bulbo, soya, aguacate, (Evaluaciones agropecuarias municipales, EVA, 2014)

De esto, solo cuatro productos cumplen con los criterios y supuestos establecidos (café, cacao, ají y aguacate), para abordar el análisis de los efectos del conflicto armado en la producción agrícola campesina, en el período de estudio.

Para establecer el comportamiento de los datos tabulados, se le hizo a cada una de las variables (ají, cacao, café, aguacate) tasa de desplazamiento, tasa de homicidios, masacres y tasa de secuestros; las transformaciones correspondientes, determinando su simetría o asimetría, así como su homocedasticidad y de ello su posterior análisis estadístico.

De la observación anterior, y como consecuencia de los resultados obtenidos se procede a transformar los datos en logaritmos, correspondientes a las variables analizadas y relacionando la variable desplazamiento, masacres, homicidios y secuestros con cada una de las variables ají, cacao, aguacate y café.

Posteriormente, se declara el análisis como serie de tiempo, a partir de lo cual se observa la correlación y regresión correspondiente de las variables en un período de 24 años (1991-2014).

\section{Análisis de datos}

Partiendo de la teorización de la economía campesina y el conflicto armado, así como la contextualización académica, político, social, territorial y económica; este capítulo presenta comparativamente las diferentes tendencias que el conflicto armado tiene en la oferta familiar campesina, en cinco municipios del departamento del Meta, determinando su relación y posterior estimación del impacto económico generado entre los años (1991-2014). De esta manera la región de estudio está limitada por los municipios de Mesetas, Vistahermosa, San Juan de Arama, La Uribe y La Macarena, los cuales hicieron parte de la zona de distensión en los años 1998-2012 (figura 1).

\section{Oferta campesina en la región de estudio}

Producción de aguacate 1991-2014 (municipios zona de estudio).

El principal productor de Aguacate resultó ser el municipio de Mesetas con una producción en toneladas que oscila entre los 1800 ton. (1991) y 0 ton. (2009), a partir del año 2010 se reporta nuevamente oferta de este producto; hasta el punto de que en el 2014 se establece una oferta productiva de 1500 ton. La tendencia productiva inicia su declive constante en 1995 y termina en los años 2009 y 2010 cuando inicia un crecimiento productivo significativo, reportándose en el 2014 la producción de 1500 ton de aguacate, como ya fue mencionado. Los datos resaltan que el período comprendido entre el 2000 y 2010 prácticamente es improductivo y la tendencia de 
decrecimiento es contundente hasta el punto de no haber producción; posterior a este período se evidencia una recuperación importante de la oferta de aguacate en este municipio, casi comparable a la producción de los años noventa, sobre todo al inicio de la zona de distensión.

Ahora bien, como segundos productores de aguacate, se destacan los municipios de Vistahermosa y San Juan de Arama; teniendo en cuenta la similitud en cuanto a la cantidad productiva. Sin embargo, sus tendencias claramente siguen el mismo patrón, diferenciándose, sobre todo en el período 2006-2009, cuando se observa una recuperación de la producción para el caso del municipio de San Juan de Arama, llegando a 600 ton producidas en el 2014, contrario a la tendencia productiva de Vistahermosa, la cual prácticamente no se ha recuperado.

En tercer lugar, se encuentran los municipios de La Macarena y La Uribe, los cuales participan productivamente en cantidades pequeñas comparadas con los municipios antes analizados. Es así que la producción de aguacate en La Macarena, osciló entre las 34 y 4 ton con tendencia de decrecimiento constante en el período 2000-2010 a partir del cual se observa una ligera recuperación productiva. La Uribe, sigue un comportamiento similar, pero con una producción ínfima entre el período 2007-2009 (figura 2).

\section{Producción de Ají 1991-2014 (municipios zona de estudio).}

La producción de ají en los cinco municipios de estudio es semejante; la razón tiene que ver con la complejidad a la hora de cosechar este producto, las familias campesinas cultivan y cosechan en cantidades pequeñas para satisfacer las necesidades netamente locales y regionales, pues su comercialización nacional e internacional es incipiente, prácticamente nula. Ahora bien, desde el punto de vista tendencial la producción tuvo para todos los casos una dinámica significativamente parecida, con una disminución paulatina de la producción en los años noventa, con una muy poca productividad a partir del 2003 y una recuperación desde el 2010, salvo para el caso del municipio de La Macarena.

El municipio con mayor producción corresponde a San Juan de Arama, teniendo en cuenta que en 1991 tuvo una producción de 3,30 ton; seguido por Vistahermosa con un máximo productivo de 2,30 ton y a continuación los municipios de La Macarena, La Uribe y Mesetas, respectivamente. En el caso de La Macarena su producción de Ají no evidencia recuperación productiva a 2014, como sí lo demuestran los demás municipios objeto de este estudio (figura 3).

\section{Producción de cacao 1991-2014 (municipios zona de estudio).}

En el caso de la producción de cacao y desde un punto de vista cuantitativo, se puede inferir que los municipios con menor producción son La Macarena y La Uribe, con un comportamiento similar en el período 1991-2000 a partir del cual se 
evidencian diferencias en la producción, teniendo en cuenta que para el caso de La Uribe el declive de esta es muy fuerte; al punto de tener producción cero en 2005, mientras que en La Macarena se observa una producción mínima en 2008 (15 ton). A partir del año 2010 se observa una recuperación importante de la producción sobre todo para el caso de La Uribe, anotando que La Macarena presenta un descenso importantísimo en los años 2013 y 2014.

Figura 1. Mapa región de estudio (municipios mesetas, Vistahermosa, La Uribe, La Macarena, San Juan de Arama)

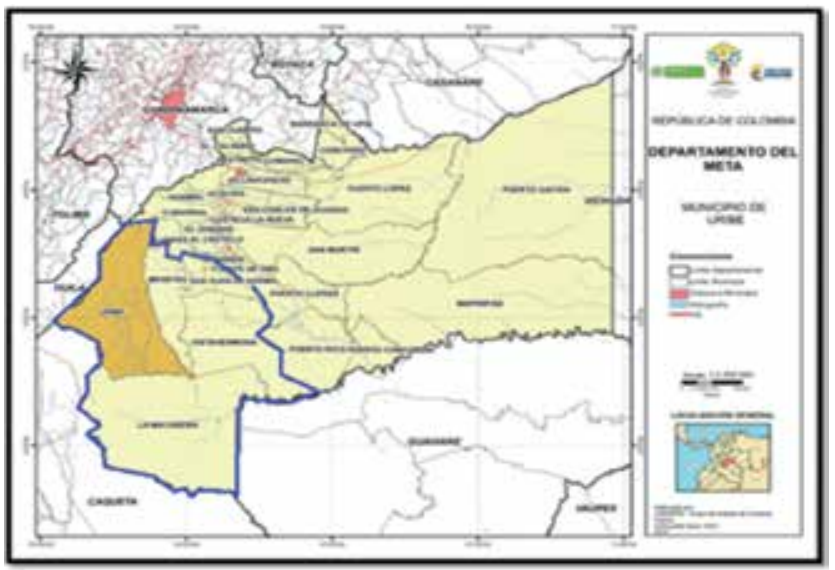

Fuente: Gobernación del Meta (modificado autor).

Figura 2. Producción de aguacate (ton)

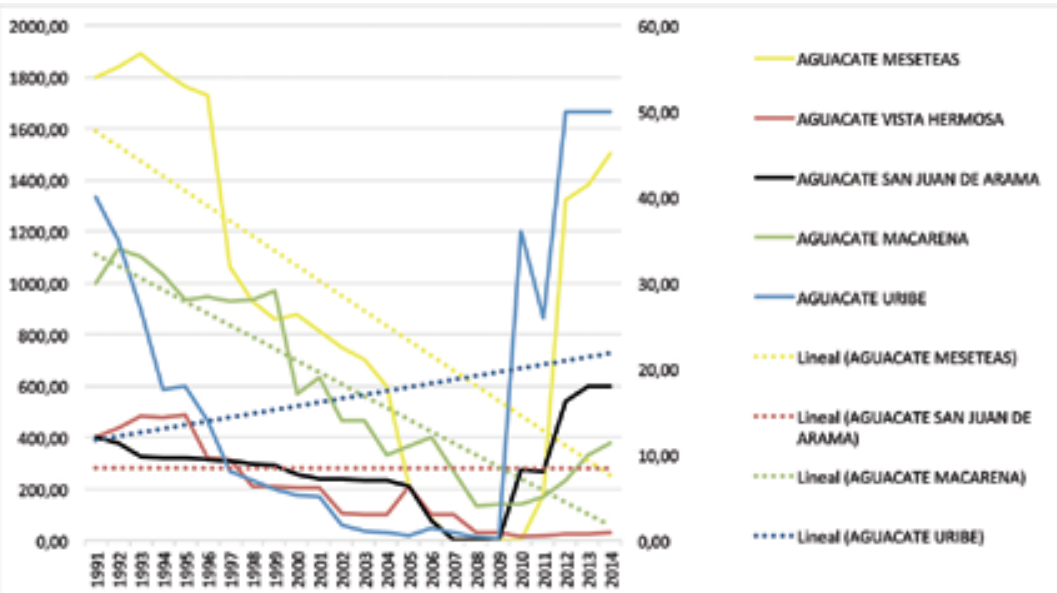

Fuente: el autor. 
Figura 3. Producción de ají (ton)

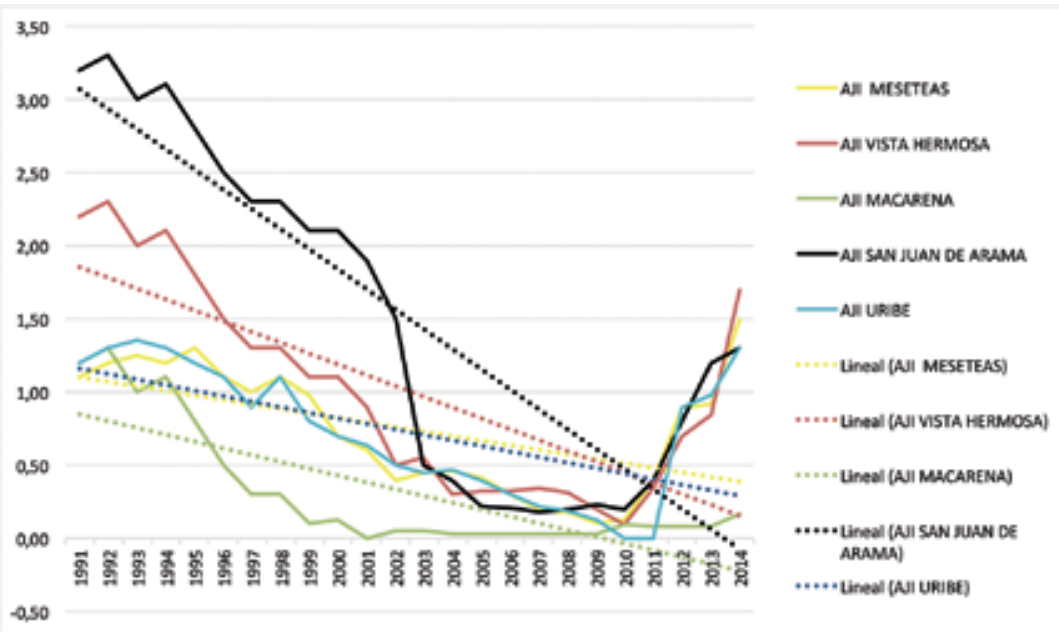

Fuente: el autor.

San Juan de Arama presenta una producción promedio mayor a los municipios anteriormente analizados, con un comportamiento que inicia su descenso constante en 1991 y que termina en 2011, con una fuerte caída en el período 2002-2008. La recuperación de la producción se evidencia entre los años 2012 a 2014, llegando a las 69 toneladas en este último año. Los municipios de Mesetas y Vistahermosa son especiales, teniendo en cuenta que son los mayores productores de cacao, con una tendencia similar a los demás municipios, pero con un impacto negativo mucho mayor.

Lo anterior, si se observa la pérdida productiva en ambos casos donde, por ejemplo, Mesetas disminuye su productividad en 51\% entre 1991-2000, mientras que Vistahermosa lo hace en un 59\%, agravándose entre el 2000 y 2001; cuando disminuye la producción en $11.7 \%$ y $47 \%$, respectivamente. Ahora bien, los datos analizados demuestran que en el período 1991-2009, la producción descendió en un 97\% para el caso de Mesetas (200 ton en 1991, 6 ton en 2009); y 99,4\% en Vista Hermosa (190 ton en 1991 y 0,20 ton en 2009). Desde allí se evidencia una recuperación importante para el caso de Mesetas reportándose 98 toneladas de este producto y un muy leve desempeño para el municipio de Vistahermosa (15 ton) en este mismo año (figura 4).

\section{Producción de café 1991-2014 (municipios zona de estudio)}

Claramente el mayor productor de café en la muestra estudiada es Mesetas, donde se evidencia una producción más o menos constante, pues esta oscila entre las 433 ton (1991) y 405 ton (2005). En términos de productividad esta disminuye en un $6,46 \%$ aproximadamente, a partir del cual se observa un descenso importante; es 
decir, en el período 2005-2011 la productividad decae a un 50,61\%, recuperándose en el período 2012-2014 cuando llega a producir 553 ton de café.

San Juan de Arama sería históricamente el segundo productor, el cual evidencia una disminución productiva constante; en promedio 10 toneladas al año, que finaliza en el 2011 (una pérdida de 82,63\%), recuperándose sustancialmente en el 2012 a 2014 al alcanzando las 189 toneladas aún mayor a la producción presentada en 1991.

Vistahermosa, La Macarena y La Uribe presentan comportamientos productivos similares, donde se evidencian tres ciclos productivos. El primero 1991-2000, el cual muestra disminución constante de la producción, en segundo lugar 2001-2010, en el que se profundiza la improductividad cafetera acercándose a cero (2010) a excepción de La Uribe que inicia su recuperación productiva. En el tercer período 2011-2014, presenta disparidades, es decir, para el caso de Vistahermosa se recupera en 2011 a 2012 observándose un aumento a 15 toneladas, pero descendiendo en 2013 y 2014 a 9 toneladas; La Macarena, al igual que el anterior, incrementa su producción en 2011 y 2012 (13 ton), pero con un descenso 2013 y 2014 aún mayor (1,20 ton); por último, La Uribe presenta una recuperación mayor a los demás en el período mencionado, pero a su vez también presenta en 2013 y 2014 un descenso aún mayor que los anteriores, llegando prácticamente a producción cero (figura 5).

En general la tendencia productiva de aguacate, ají, café y cacao es decreciente en el período 1991-1999, afianzándose esta dinámica en el período 2000-2010 para todos los casos analizados, hasta el punto de encontrar producción cero; y entre el período 2011-2014 se observan recuperaciones productivas, con algunas excepciones.

\section{Conflicto armado en la zona de estudio}

El departamento del Meta históricamente ha sentido el flagelo del conflicto armado, por sus características geoestratégicas, políticas, económicas y sociales, sin embargo, es necesario comprender la dinámica tendencial de esta variable en los municipios que hicieron parte de la zona de distención (Guerrilla de las FARC EP y Gobierno Nacional) y arremetidas paramilitares.

De esta manera, en razón del conflicto armado se analizaron cuatro categorías, desplazamiento, homicidios, masacres y secuestros; para comprender su dinámica y así abordar el análisis de los efectos de este en la producción agrícola familiar campesina, en el período de estudio.

Adicionalmente es importante manifestar que ante la posibilidad de tener al menos tres instituciones en el país, que desarrollan actividades para presentar información alrededor de las categorías analizadas y que presentan disparidades significativas, fue necesario adoptar como base científica, los datos suministrados por el Observatorio del Programa Presidencial de DH y DIH, de la Vicepresidencia de la República. 
Figura 4. Producción de cacao (ton)

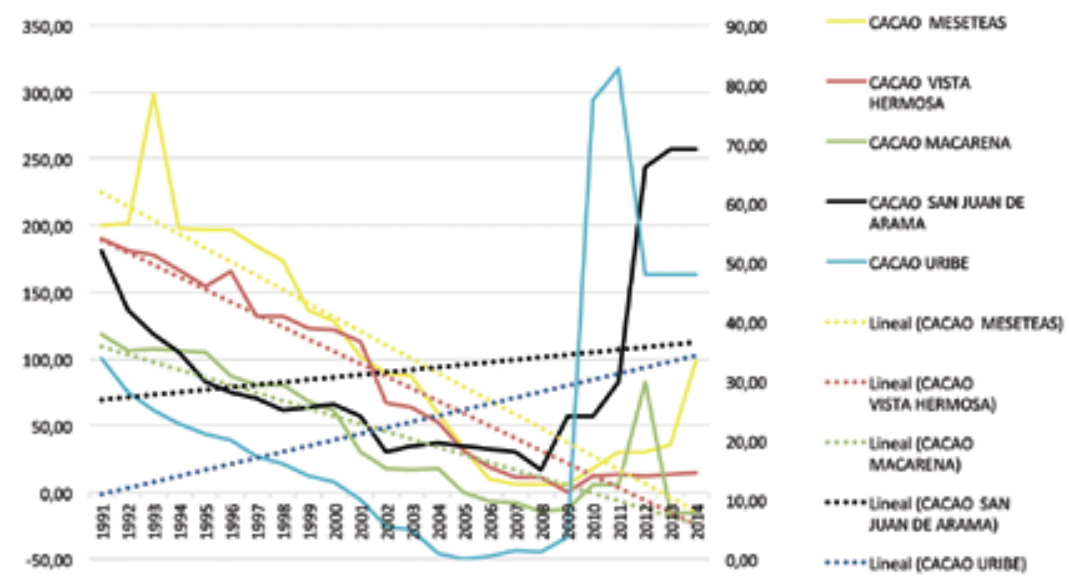

Fuente: el autor.

Figura 5. Producción de café (ton)

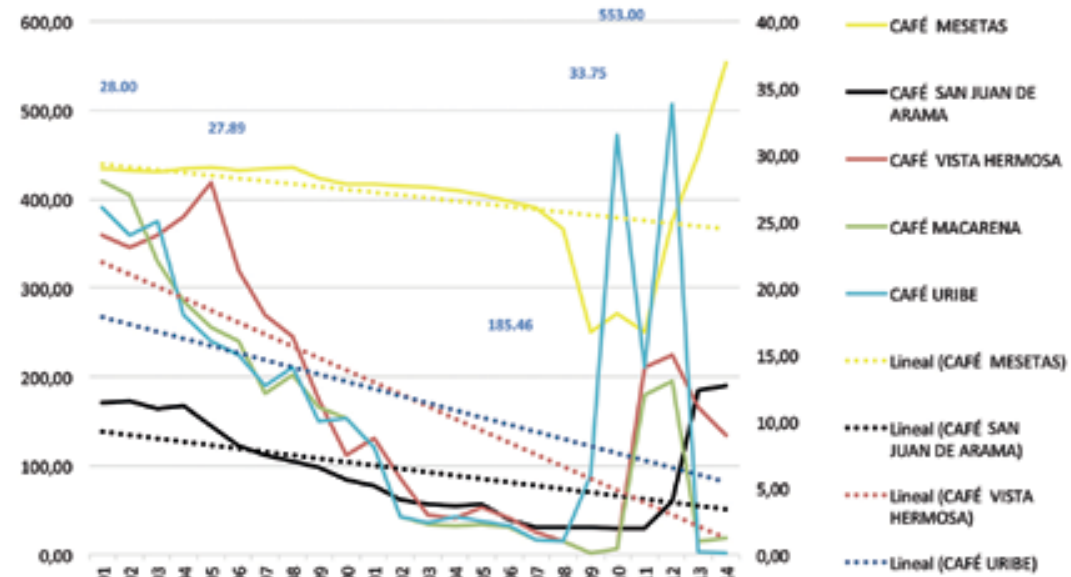

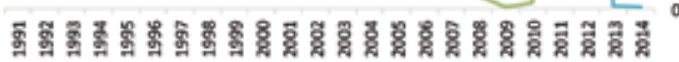

Fuente: el autor.

\section{Tendencia desplazamiento (1991-2014)}

La figura 6 muestra un patrón tendencial similar para todos los casos, donde se observan dos picos para cada uno, los cuales se ubican en el 2001-2002 y 2004-2007, 
respectivamente. Para el caso de Mesetas, Vistahermosa y San Juan de Arama el segundo pico de desplazamiento es mayor que en el primero, mientras que para La Uribe y La Macarena estos son más o menos parecidos. Vistahermosa es el municipio con mayor reporte de desplazamiento, llegando a tener una tasa máxima de 26.598 $(26,5 \%)$, es decir, un cuarto de la población desplazada tan solo en el 2006 seguido por los municipios de San Juan de Arama y Mesetas con un máximo histórico de 10.785 $(10,7 \%)$ y 9.293 (9,2\%), respectivamente en el mismo año. El municipio de La Uribe presenta su mayor pico años antes (2002), con una tasa registrada de desplazamiento de 6205 por cada 100.000 habitantes $(6,2 \%)$ pero menor a los ya mencionados y La Macarena presenta su máxima tasa en el 2006 (4411) es decir un porcentaje de desplazamiento poblacional de $4,4 \%$.

Está claro que en términos de esta categoría del conflicto armado el desplazamiento inicia para todos los casos una tendencia de incremento constante desde 1991, con tasas por debajo del 0,7\%, llegando en 1999 al 3\%. Posterior a este período los comportamientos para cada municipio son diferentes, pues en algunos casos se maximiza más que en otros; pero en general agudizándose entre 2000-2008, a partir del cual se evidencia un comportamiento de descenso, hasta llegar al final del período de estudio (2014), con una tasa menor al 0,9\% a excepción del municipio de Mesetas el cual no registró hechos de desplazamiento (figura 6).

Figura 6. Tendencia desplazamiento (tasa por cada 100.000 habitantes)
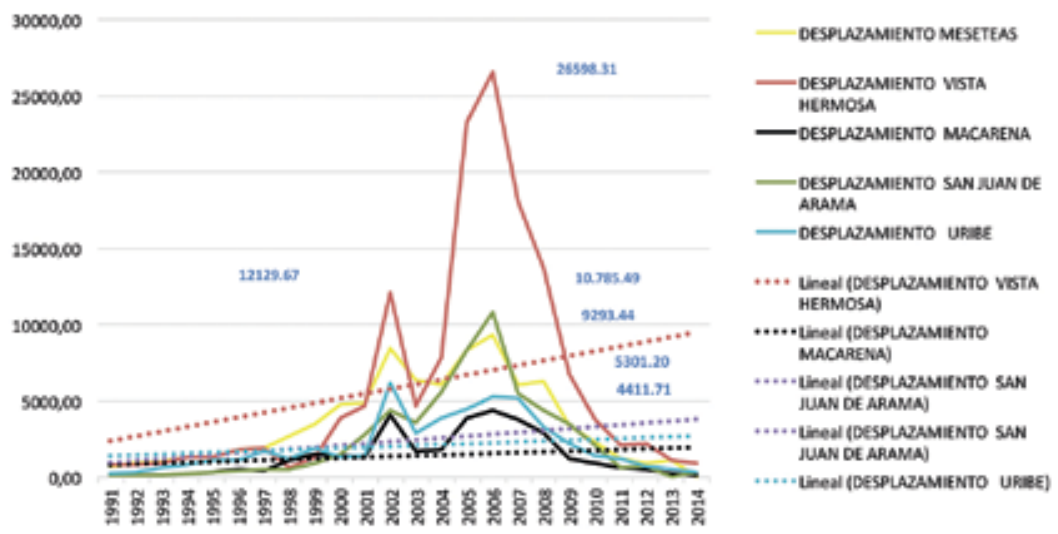

Fuente: el autor.

\section{Tendencia homicidio (1991-2014)}

Las tasas de homicidios observadas en la figura 7, muestran un comportamiento volátil para el período (1991-2014), en todos los casos. Sin embargo, es importante mencionar la disminución de la tasa de homicidios entre el período 1999-2001 
para los municipios de Mesetas, Vista Hermosa, La Macarena y La Uribe (zona de distensión), exceptuando el municipio de San Juan de Arama la cual tuvo una tasa máxima de 115,95 correspondiente al 1,15\% de la población en el 2000.

Ahora bien, la categoría tasa de homicidios sigue el mismo comportamiento que la dinámica correspondiente a tasa de desplazamiento concordante con el período 2000-2008 donde se acentúa sistemáticamente alcanzando los siguientes picos máximos. Vistahermosa $(459,31)$ en 2006, San Juan de Arama $(449,42)$ en 2003, La Uribe $(413,04)$ en 2009, Mesetas $(353,93)$ en 2003, La Macarena $(220,78)$ en 2003, posterior a 2008 se presenta un descenso paulatino en todos los municipios a 2014 (figura 7).

Teniendo en cuenta lo anterior, parecería que la tasa de homicidios permite inferir que como consecuencia se presenta el posterior desplazamiento, esto se tendrá que analizar estableciendo su correlación y posterior regresión para cuantificar el impacto específico.

Figura 7. Tendencia homicidios (tasa por cada 100.000 habitantes)
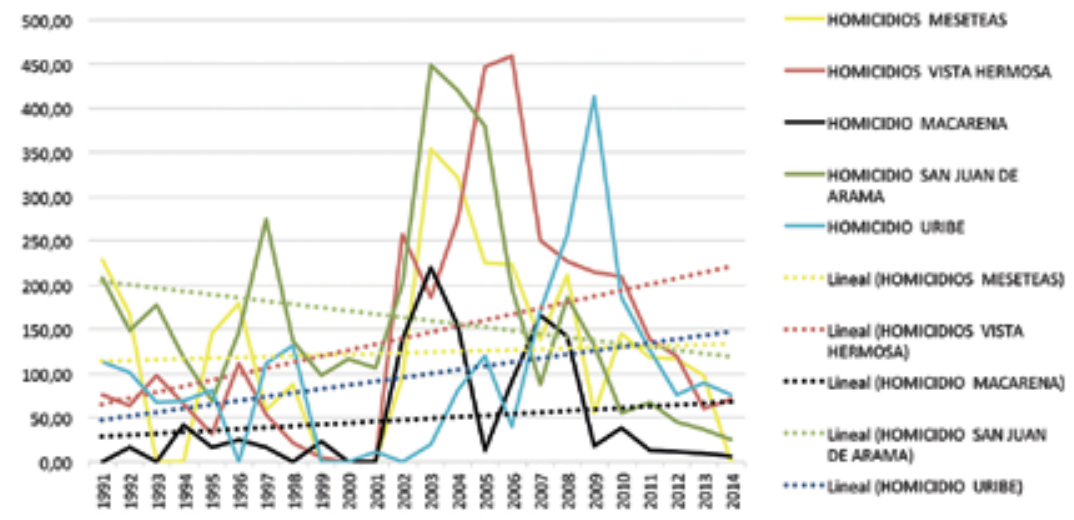

Fuente: el autor.

\section{Tendencia masacres (1991-2014)}

El municipio que en el período de estudio presentó la mayor cantidad de eventos registrados correspondientes a esta categoría, es La Macarena, con un caso (1996) y (2002), respectivamente, mientras que en el 2010 se presentaron dos eventos; seguido por Vistahermosa con un evento en 1996 y otro en 2008. Los eventos referenciados resultaron dos años antes del inicio de la zona de distensión y posterior a este proyecto de paz. 
San Juan de Arama registra dos eventos en 2008, mientras Mesetas registra uno en 2006, observándose que la mayoría de eventos para el caso de todos los municipios se presenta entre el período 2002-2008 a excepción de La Uribe; la cual no presenta eventos de Masacres. Lo anterior concuerda con las categorías ya analizadas en el sentido de que este período en términos de violencia es acentuado (figura 8).

Figura 8. Tendencia masacres (eventos)

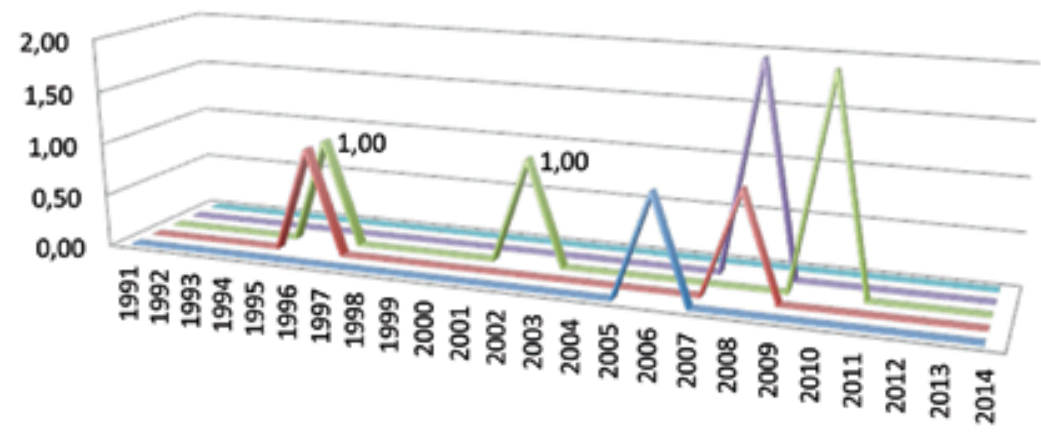

$\square$ MASACRES MESETEAS
$\square$ MASACRES MACARENA

$\square$ MASACRES VISTA HERMOSA

IMASACRES SAN JUAN DE ARAMA

Fuente: el autor

\section{Tendencia secuestros (1991-2014)}

El secuestro es una categoría que no está relacionada exclusivamente con el conflicto armado, por cuanto la delincuencia común también lo utiliza como fuente de financiación de sus actividades; este estudio lo incluye por ser uno de los flagelos presentes en el accionar, tanto insurgente como paramilitar. Es así, y al igual que la tasa de homicidios y de acuerdo con la ilustración 9, la tendencia de secuestros es volátil durante el período 1991-2014; sin embargo, se observan claramente tres períodos para todos los municipios. El primero 1995-2001 en el que se observan los mayores picos en los municipios de Mesetas y La Uribe (0,081\% y 0,059\%, respectivamente); el segundo 2002-2009, presenta a San Juan de Arama y La Uribe con mayores porcentajes $(0,11 \%$ y $0,072 \%$, respectivamente), de igual manera, Vistahermosa registra aumentos de la tasa de secuestros en este período. El tercer período (2010-2014) refleja un pequeño ciclo de secuestros para los municipios de Mesetas, Vistahermosa y San Juan de Arama, con cero secuestros en La Uribe y La Macarena, esta última e históricamente con la menor tasa de secuestros de los cinco municipios analizados. 
Figura 9. Tendencia secuestros (tasa por cada 100.000habitantes)

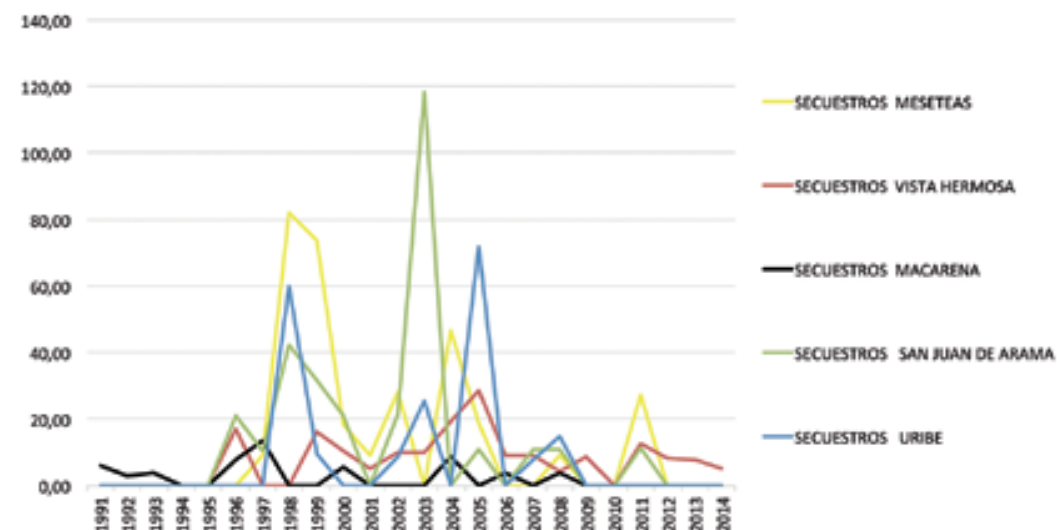

Fuente: el autor.

\section{Relación del conflicto armado en la actividad productiva familiar campesina}

Analizadas las tendencias productivas y conflicto armado a razón de desplazamiento, homicidios, masacres y secuestros, se contrasta los comportamientos de las variables en el período de estudio, con el objeto de observar sus líneas de tendencia y su relación. Para describir lo enunciado, el análisis se realiza por municipios y para cada uno de los productos que hacen parte de la oferta familiar campesina estudiada (aguacate, ají, cacao y café).

Municipio de Mesetas: Variable conflicto armados relacionado con producción agrícola campesina.

Las figuras muestran una tendencia indirecta entre producción campesina y la categoría desplazamiento para todos los casos, y las demás categorías de conflicto armado restantes parecerían influir en el comportamiento de la tasa de desplazamiento. Es importante mencionar que la tendencia de las variables producción y conflicto armado a razón de desplazamiento se cruzan entre los años 2000 y 2010, pues es el período donde se incrementa con mayor contundencia la tasa de desplazamiento y disminuye la oferta familiar campesina para los productos analizados.

En términos de oferta agrícola campesina, la producción de aguacate fue la más afectada como lo muestra la ilustración 10, llegando a producción cero en 2008 y 2009, recuperándose en 2011. Por otro lado, para el caso del ají y aunque menor en cuanto a producción comparativamente hablando, presenta un comportamiento similar con su correspondiente recuperación (figuras 10 y 11). 
Figura 10. Relación aguacate y conflicto (Mesetas)

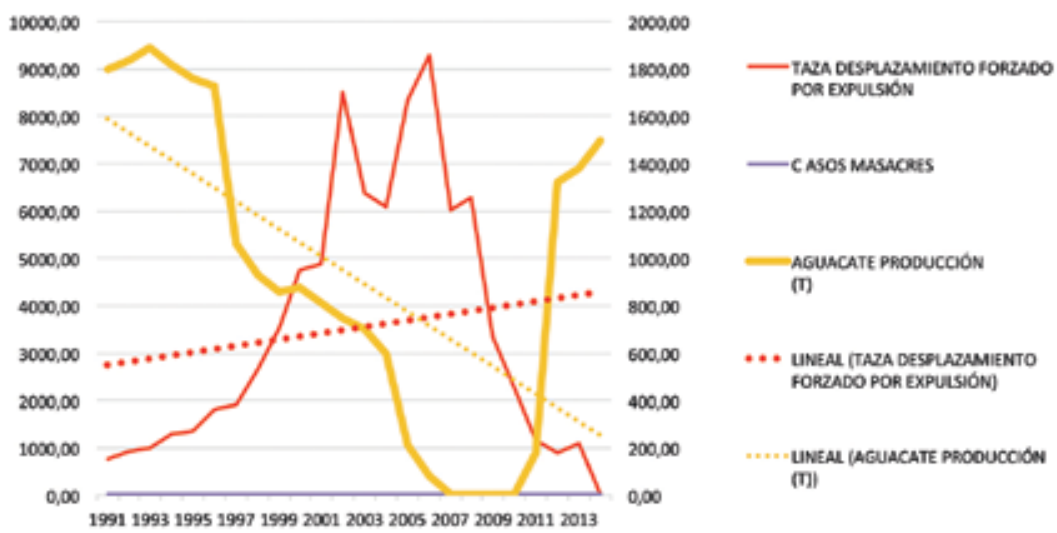

Fuente: el autor.

Figura 11. Relación ají y conflicto (Mesetas)

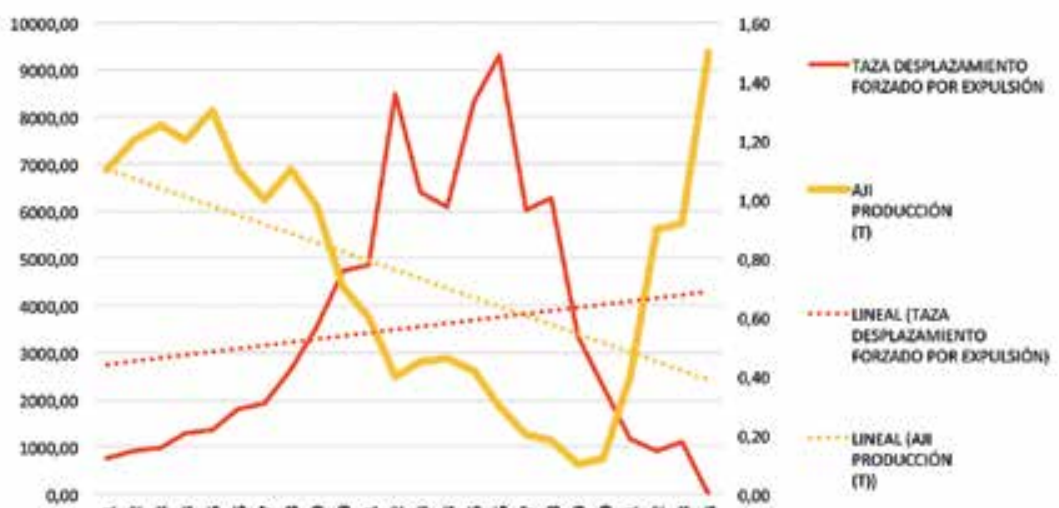

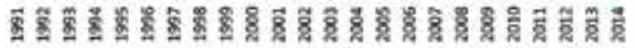

Fuente: el autor.

Ahora bien, aunque la producción de cacao y café en el municipio de Mesetas también presentaron descensos en el período de estudio, estos no tuvieron tendencias tan marcadas sino más bien constantes (figuras 12 y 13). 
Figura 12. Relación cacao y conflicto (Mesetas)

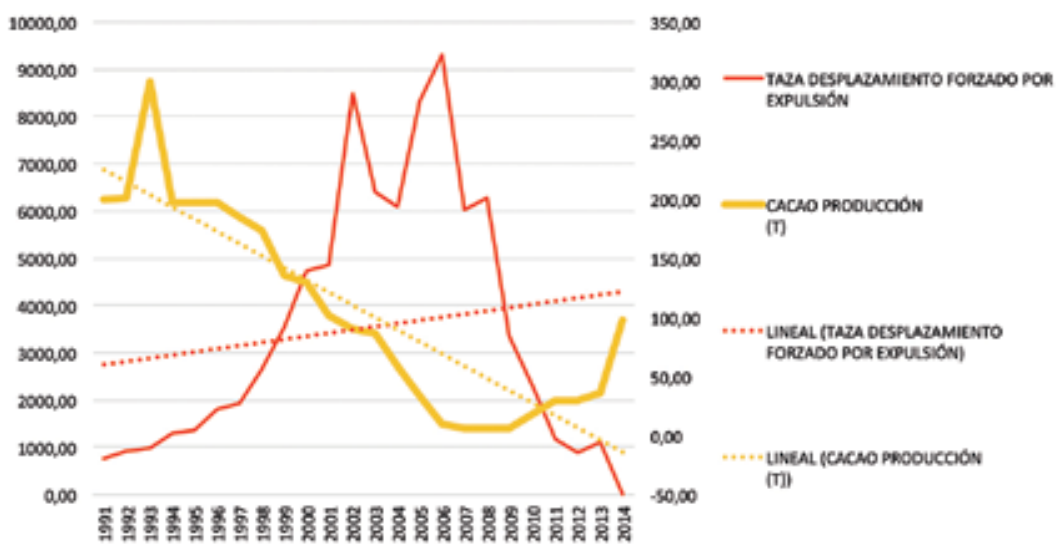

Fuente: el autor.

Figura 13. Relación café y conflicto (Mesetas)

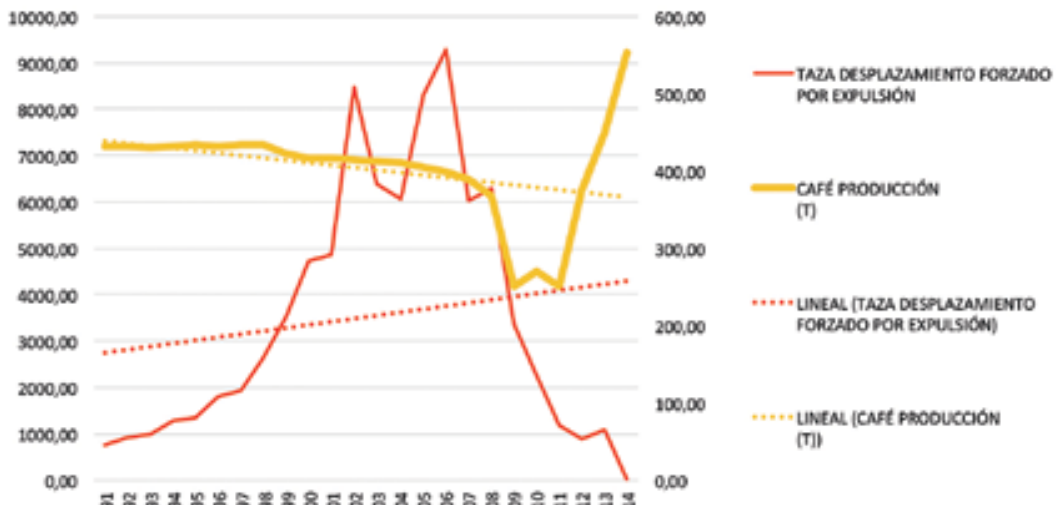

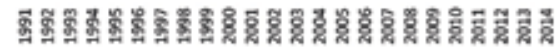

Fuente: el autor.

Municipio de Vistahermosa: Variable conflicto armado relacionado con producción agrícola campesina.

La relación entre desplazamiento y producción es inversa para todos los casos (aguacate, ají, cacao y café), las líneas de tendencia evidencian su dinámica. Igualmente se muestra recuperación en la oferta productiva campesina en el caso 
de ají y café a partir de 2010, mientras que la producción de aguacate y cacao no se ha podido recuperar satisfactoriamente al término del período de estudio, 2014. Así mismo, analizando las ilustraciones, se observa que posterior a los mayores picos e inmediato descenso de la tasa de desplazamiento (aproximadamente tres años), la producción inicia su aumento paulatino (aguacate y cacao) y ostensiblemente (ají y café) (figuras 14, 15, 16 y 17).

Figura 14. Relación aguacate y conflicto (Vistahermosa)

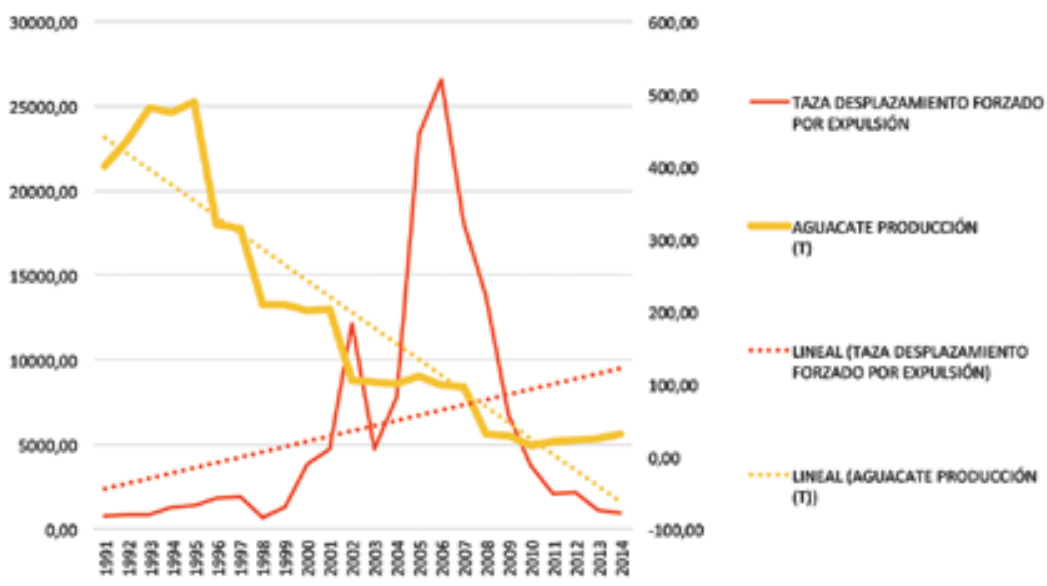

Fuente: el autor.

Figura 15. Relación ají y conflicto (Vistahermosa)

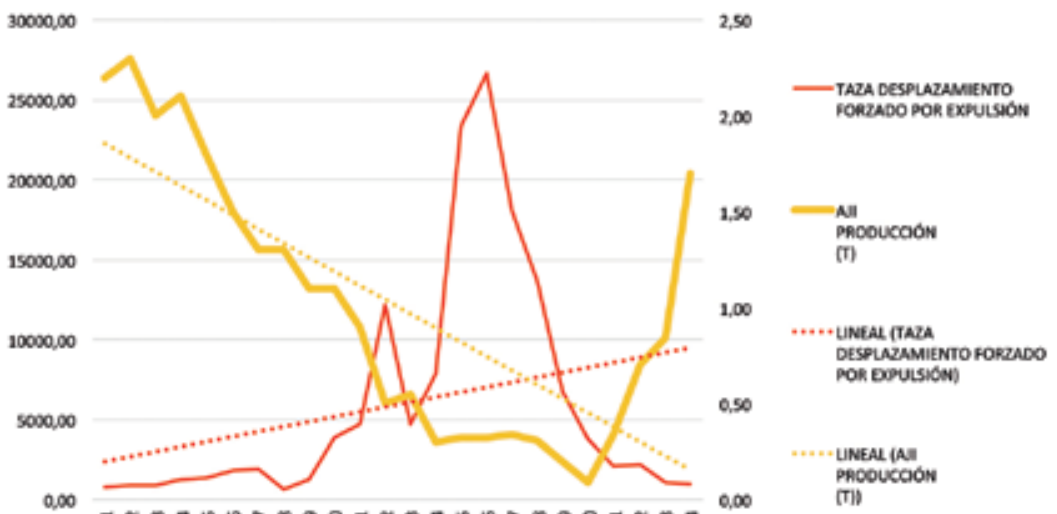

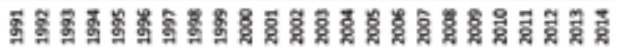

Fuente: el autor. 
Las categorías homicidios, secuestros y masacres inciden fuertemente en el desplazamiento poblacional, pero de las familias campesinas en mayor proporción, que la del terrateniente o mediano productor en este municipio, la anterior mención, se basa en entrevista no estructurada a pobladores que tienen la memoria histórica del municipio de acuerdo con sus vivencias. Esto habría que corroborarlo con las pruebas estadísticas pertinentes.

Figura 16. Relación cacao y conflicto (Vistahermosa)

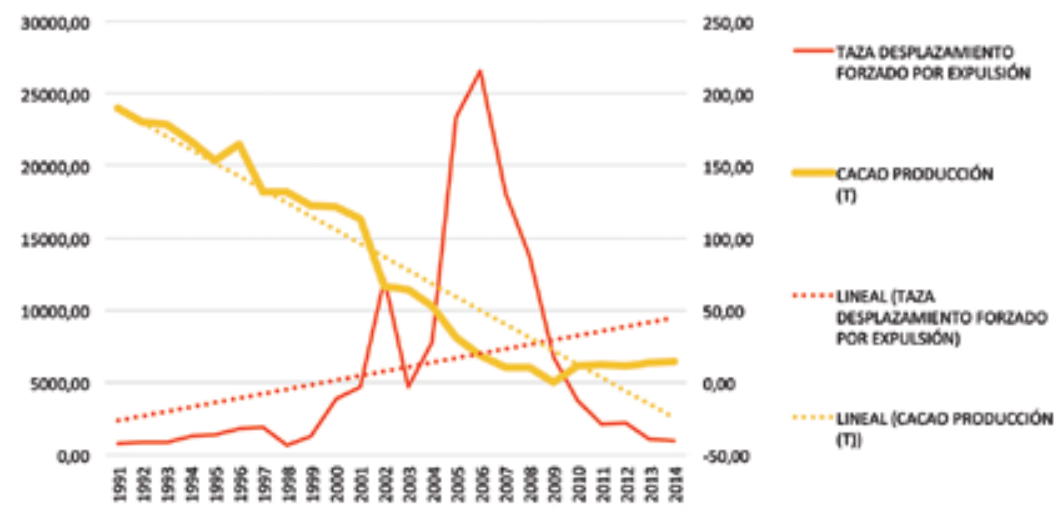

Fuente: el autor.

Figura 17. Relación café y conflicto (Vistahermosa)
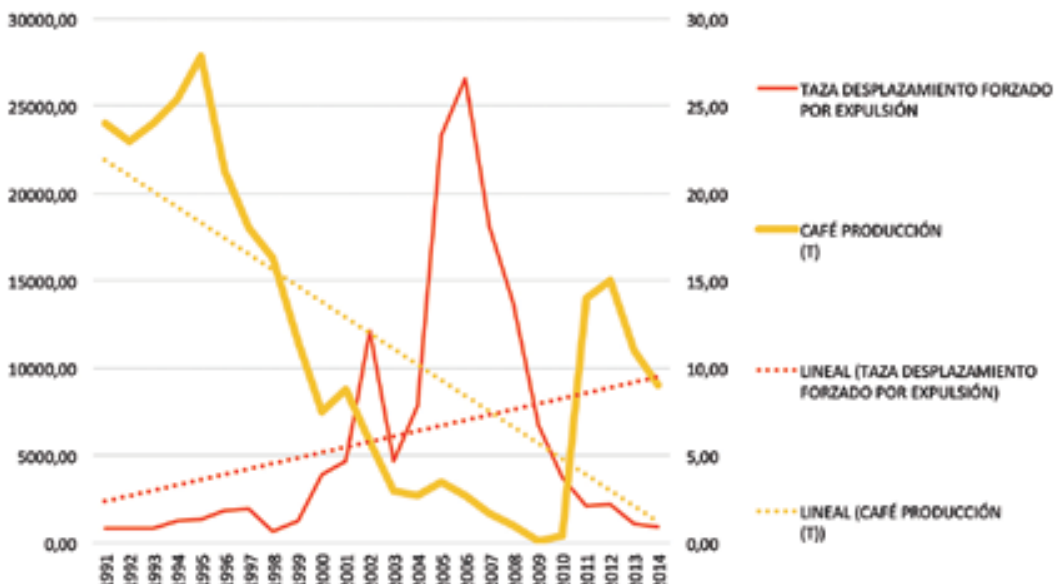

Fuente: el autor. 
Municipio La Macarena: Variable conflicto armado relacionado con producción agrícola campesina.

La Macarena evidencia el mismo comportamiento, tanto para las variables oferta productiva familiar como el conflicto armado, resultando una relación inversa y al igual que en los municipios de Mesetas y Vistahermosa la crisis se agrava en el período 2000-2001. (figuras 18, 19, 20 y 21).

Figura 18. Relación aguacate y conflicto (La Macarena)

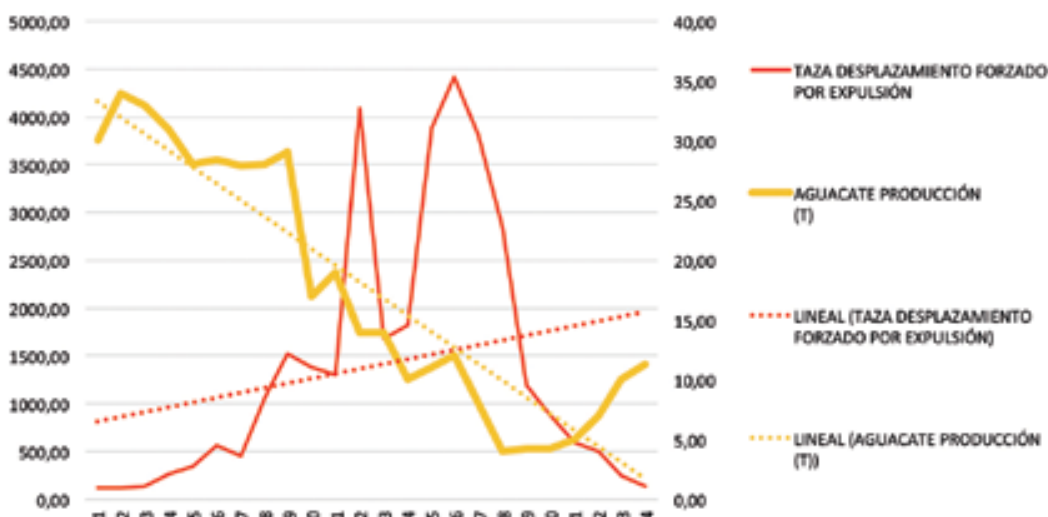

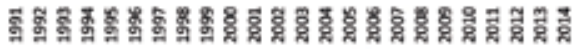

Fuente: el autor.

Figura 19. Relación aji y conflicto (La Macarena)

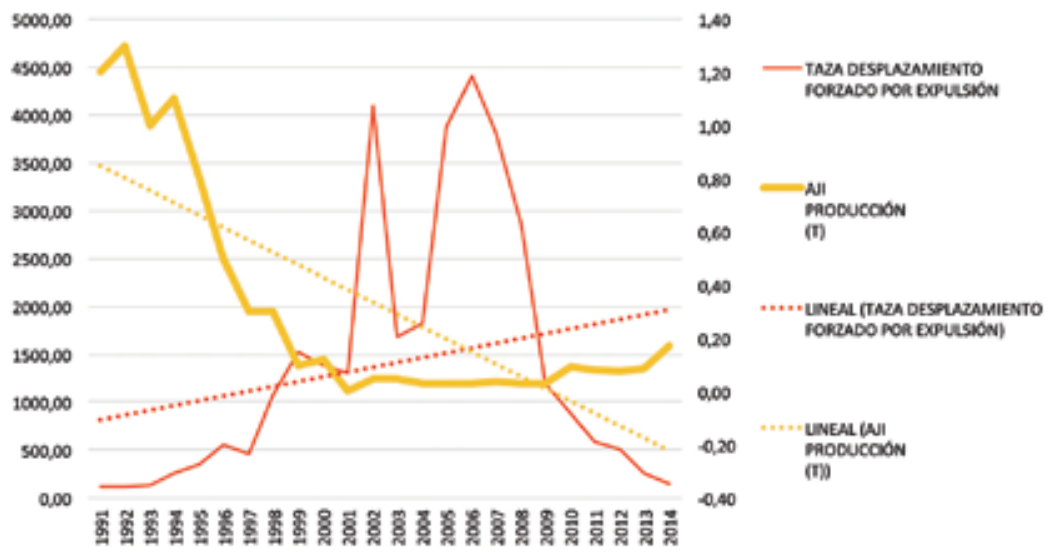

Fuente: el autor. 
Figura 20. Relación cacao y conflicto (La Macarena)

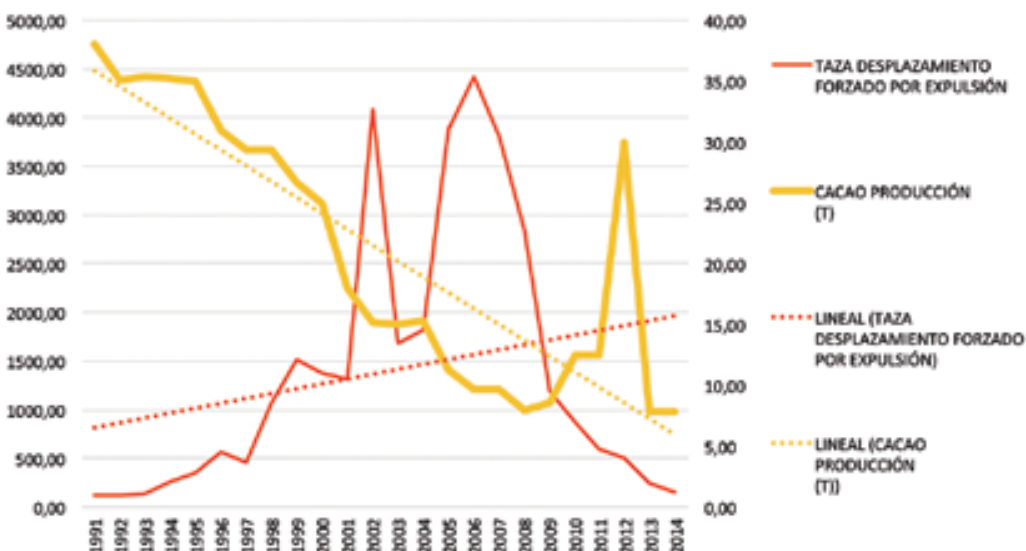

Fuente: el autor.

Figura 21. Relación café y conflicto (La Macarena)
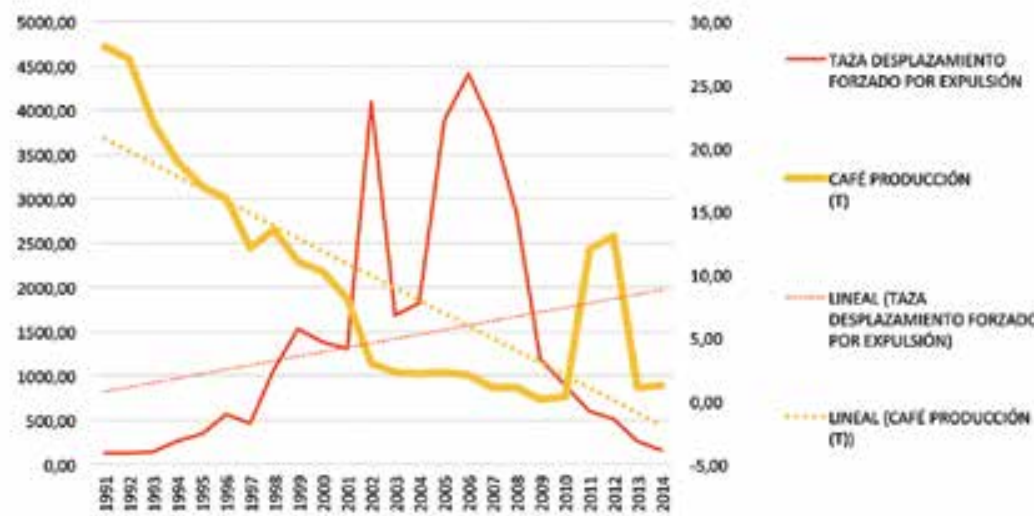

Fuente: el autor.

La tasa de desplazamiento en este período presenta dos picos máximos, iniciando el primero inmediatamente posterior al término de la zona de distención y el proceso de paz, pero también con el inicio de la arremetida paramilitar en la región. Como consecuencia la disminución de la actividad productiva de las familias campesinas en este período histórico, evidenciándose a su vez para la producción de aguacate, cacao y café una fuerte recuperación a partir del 2010, mientras que el ají de forma leve pero constante al alza. 
Según los habitantes del municipio, al ser entrevistados indican que no solamente la contraofensiva paramilitar afectó el crecimiento migratorio de La Macarena, sino que también la contraofensiva de las fuerzas del Estado provocaron afectaciones en la población civil, entre otros con falsos positivos.

Municipio San Juan de Arama: Variable conflicto armado relacionado con producción agrícola campesina.

Al igual que el municipio de Mesetas, en San Juan de Arama la producción de aguacate también sufre una fuerte caída, llegando a producción cero. Aunque este municipio no hizo parte territorial de la zona de distención, como vecino sí evidencia los impactos del conflicto armado; a razón de la oferta de producción familiar campesina (figuras 22 y 23).

Igualmente, se evidencia el comportamiento generalizado de los municipios antes analizados, entre el período 2000-2010, pero en el caso de todas las producciones estas se recuperan posterior a los picos máximos de desplazamiento, unas en mayor proporción que otras (figuras 24 y 25).

\section{Municipio La Uribe: Variable conflicto armado relacionado con producción agrícola campesina.}

Este municipio, considerado históricamente como el centro operativo del grupo guerrillero FARC EP, presenta cuatro picos de desplazamiento, dos en la década de los noventa y dos en el período 2002-2008, observándose una tendencia de decrecimiento constante y marcado en la producción de aguacate, ají, cacao y café; comportamiento que cambia a partir del 2008 para todos los casos, recuperándose contundentemente en 2014.

Figura 22. Relación aguacate y conflicto (San Juan de Arama)

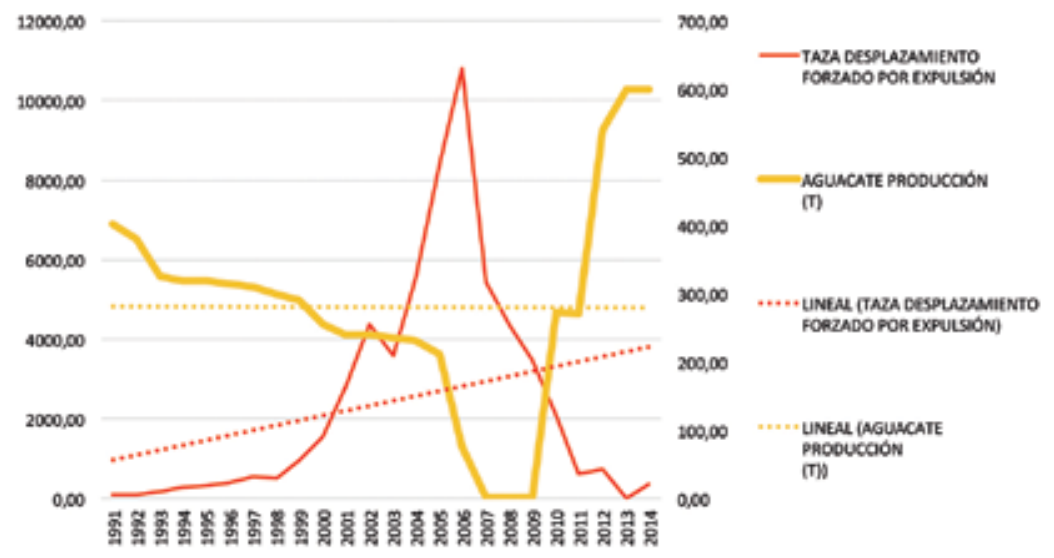

Fuente: el autor. 
Impacto económico de la violencia armada sobre la producción campesina...

Figura 23. Relación ají y conflicto (San Juan de Arama)
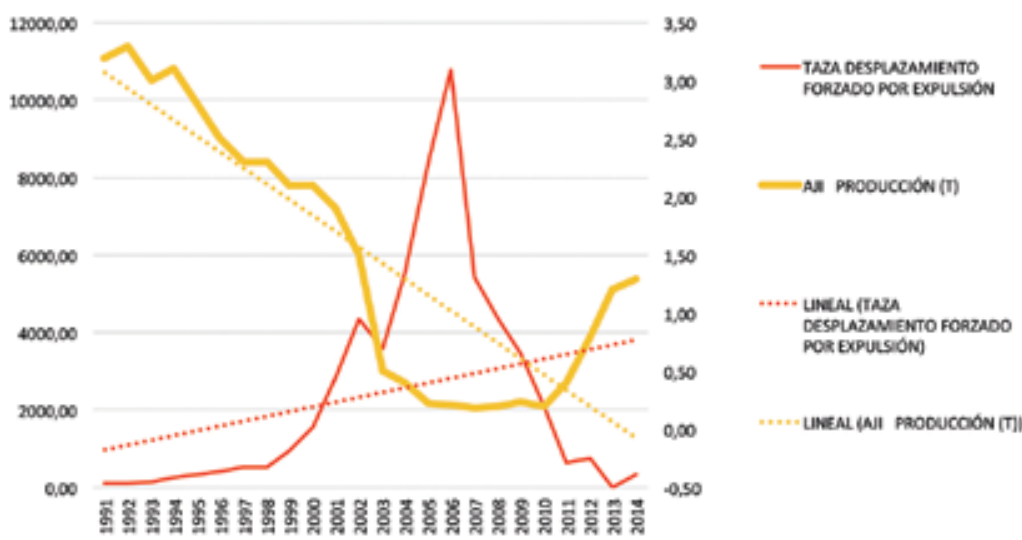

Fuente: el autor

Figura 24. Relación cacao y conflicto (San Juan de Arama)

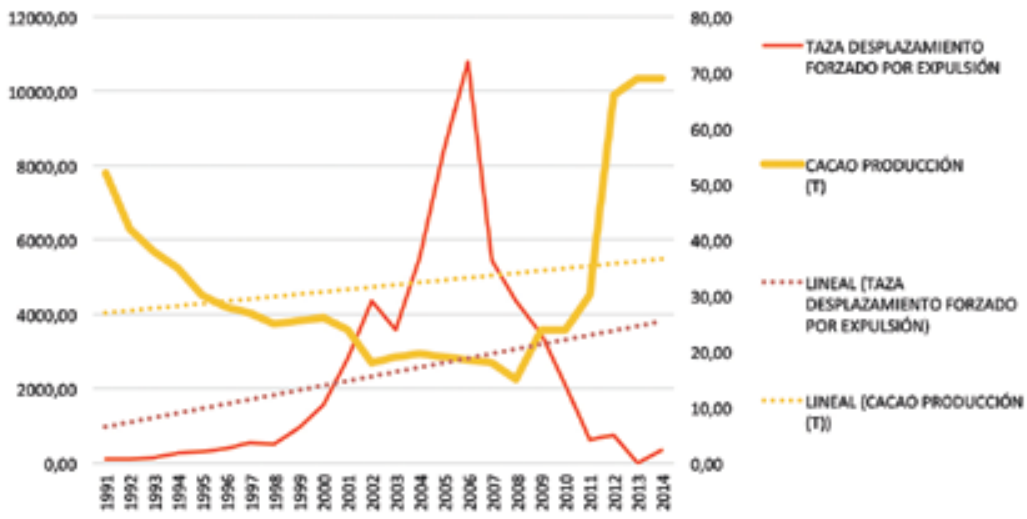

Fuente: el autor. 
Figura 25. Relación café y conflicto (San Juan de Arama)

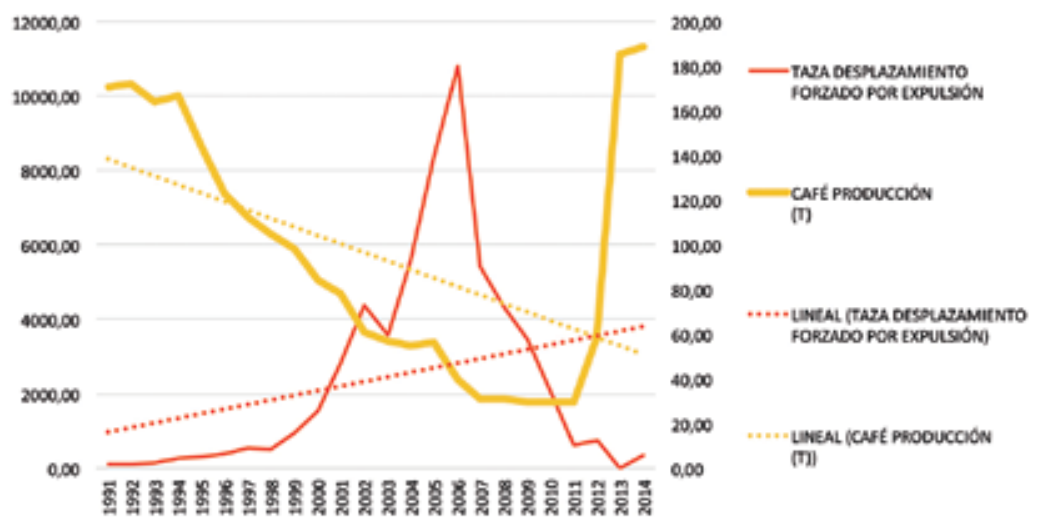

Fuente: el autor.

Figura 26. Relación aguacate y conflicto (La Uribe)

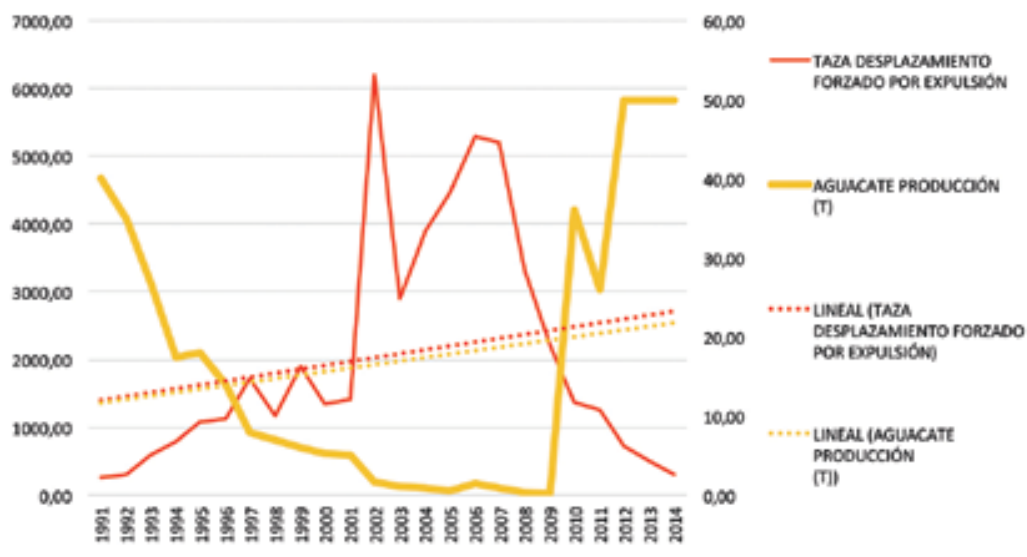

Fuente: el autor.

Así mismo, y de acuerdo con entrevistas realizadas a pobladores de este territorio, las incursiones de las fuerzas del Estado a partir del 2002 también han sido una constante desequilibradora en la población de este municipio del sur del Meta. La lucha contra la insurgencia colombiana ha dejado a la población en medio de las hostilidades y la sospecha, por cuanto el campesino puede ser confundido en muchos casos como guerrillero o auxiliador de este ejército irregular. 
Figura 27. Relación aji y conflicto (La Uribe)

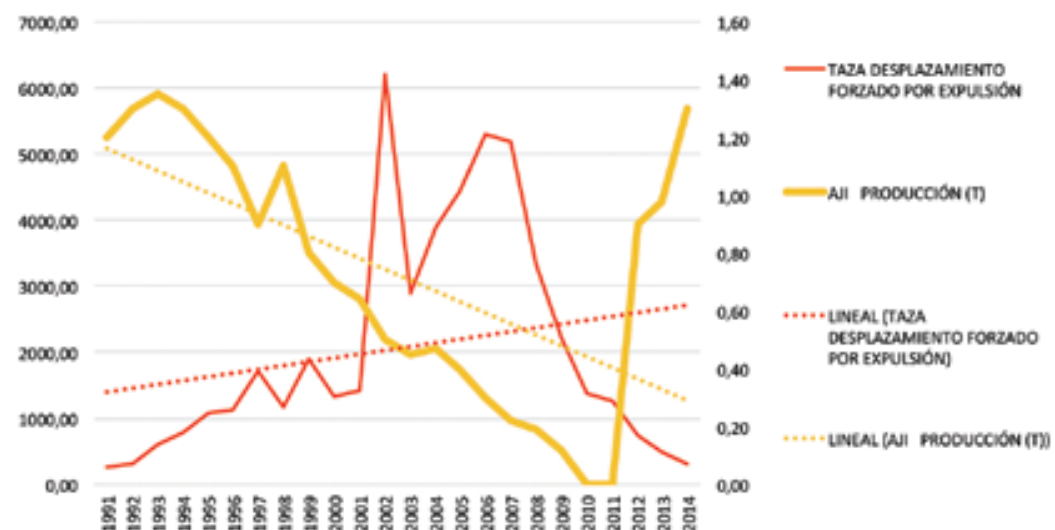

Fuente: el autor.

Figura 28. Relación cacao y conflicto (La Uribe)

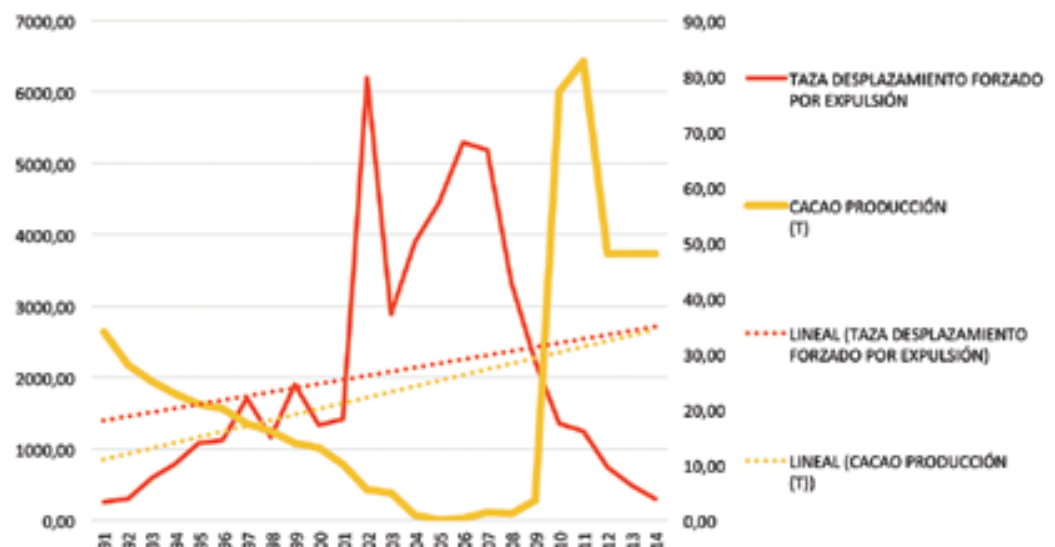

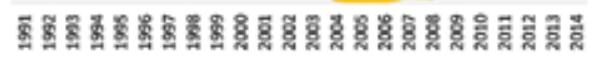

Fuente: el autor.

\section{Resultados}

La metodología para este estudio se fundamenta en la construcción de una base de datos para serie en panel; que es un panel balanceado y el modelo econométrico es un panel dinámico que tiene en cuenta los municipios para estimar variable de conflicto armado, el desplazamiento, masacres, homicidios, secuestros y variables 
de economía campesina, que para este estudio es la producción en toneladas de aguacate, ají, cacao y café, por ser parte del inventario campesino de los municipios analizados. Se estima el modelo en Stata 12 para el correspondiente análisis de los resultados. La aproximación cuantitativa para los principales hallazgos empíricos y los resultados de las diferentes estimaciones se fundamentaron en el uso de varias técnicas de análisis: El uso de clústeres para agrupar los municipios de acuerdo con los eventos de desplazamiento, masacres, homicidios y secuestros, el análisis de correlaciones para determinar la relación de las variables y el uso de regresiones.

Figura 29. Relación café y conflicto (La Uribe)

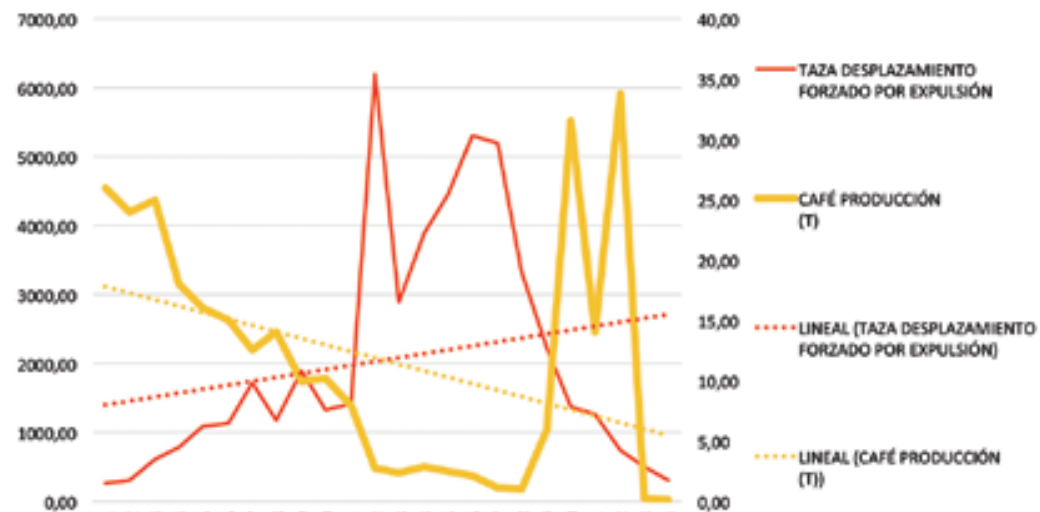

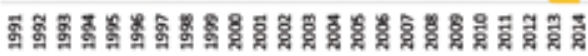

Fuente: el autor.

\section{Correlación de Pearson}

El coeficiente de correlación de Pearson se utilizó para medir la relación que puede existir entre las variables del conflicto armado y las variables de producción campesina en los cinco municipios estudiados, como se muestra a continuación:

\section{Correlación oferta campesina y desplazamiento}

Los resultados entre desplazamiento y las variables relacionadas con la producción campesina (aguacate, ají, cacao y café) muestran una correlación negativa; y en esta la más alta se encuentra en la variable ají y aguacate.

Indicando que cuando aumenta el desplazamiento la producción campesina disminuye en todas las producciones analizadas, y esta tendencia ha impactado medianamente en la producción de aguacate, ají, café y cacao toda vez que los coeficientes no son igual o mayores de 0,7 en valor absoluto (tabla 1 ). 
Tabla 1. Correlación desplazamiento y producción familiar campesina

\begin{tabular}{ccccc}
\cline { 2 - 4 } & In aguacate & In ají & In café & In cacao \\
\hline In desplazamiento & $-0,3001$ & -0.4101 & -0.2403 & -0.3625 \\
\hline
\end{tabular}

Fuente: Stata.

\section{Correlación oferta campesina y homicidios}

Para el caso de homicidios correlacionado (aguacate, ají, cacao y café) muestra una correlación negativa solo para el caso de cacao en -0,0385 (tabla 2).

Tabla 2. Correlación homicidios y producción familiar campesina

\begin{tabular}{ccccc}
\cline { 2 - 4 } & In aguacate & In ají & In café & In cacao \\
\hline In homicidios & 0.1150 & 0.0475 & 0.1800 & -0.0385 \\
\hline
\end{tabular}

Fuente: Stata.

\section{Correlación oferta campesina y masacres}

Los resultados entre masacre y las variables relacionadas con la producción campesina (aguacate, ají, cacao y café) muestran una relación negativa para todos los casos; donde la correlación significativamente más alta se encuentra en la variable aguacate. Lo que indica que cuando se presentan casos de masacre la producción campesina disminuye en todas las producciones analizadas, y esta tendencia ha impactado en mayor proporción en el tema del aguacate pues tiene una relación alta por encima del $80 \%$ (tabla 3). Entendiendo que una alta población afectada es productora de este alimento en la zona de estudio.

Tabla 3. Correlación masacres y producción familiar campesina

\begin{tabular}{ccccc}
\cline { 2 - 4 } & In aguacate & In ají & In café & In cacao \\
\hline In Masacres & -0.8289 & -0.3839 & -0.2649 & -0.2843 \\
\hline
\end{tabular}

Fuente: Stata.

\section{Correlación oferta campesina y secuestros}

Los secuestros, y según los resultados de la tabla 4, no presentan correlación negativa esperada frente a la oferta campesina (tabla 4).

Tabla 4. Correlación secuestros y producción familiar campesina

\begin{tabular}{ccccc}
\cline { 2 - 5 } & In aguacate & In aji & In café & In cacao \\
\hline In secuestros & 0.3818 & 0.3212 & 0.4822 & 0.2445 \\
\hline
\end{tabular}

Fuente: Stata. 


\section{Correlación desplazamientos con demás variables de conflicto armado}

Teniendo en cuenta que las variables desplazamiento tiene una fuerte correlación con las variables de producción, a su vez se estimó la correlación de las variables de conflicto armado entre sí, estableciendo su relación. De esto se encuentra una relación inversa entre tasas de desplazamiento y dos variables como los son masacres y secuestros ( $30 \%$ y $84,62 \%$, respectivamente), antes no evidenciados; así mismo, homicidios y secuestros (12\%).

\section{Modelo teórico}

Estimadas las correlaciones para las variables analizadas en este estudio para el período 1991-2014, y teniendo en cuenta que se ha establecido metodológicamente un análisis específico para cada una de las ofertas productivas campesinas como lo son la producción de aguacate, ají, cacao y café (variables dependientes) y la variable conflicto armado a razón de desplazamiento (variable exógena), a continuación se establecerán el correspondiente análisis a través de una regresión lineal con función muestral.

$$
y=\beta_{1}+\beta_{2} X+u \text { Ecuación } 1 .
$$

Donde;

$\mathrm{y}=$ Oferta productiva familiar campesina (aguacate, ají, cacao, café)

$\mathrm{X}=$ Desplazamiento

$\beta_{1}=$ Constante del modelo

$\beta_{2}=$ Pendiente

$\mathrm{u}=$ Perturbación aleatoria

El objetivo principal de este modelo de regresión es la estimación de $\beta 1$ y $\beta 2$ a partir de una muestra dada. Siendo la función de regresión muestral (FRM) la contrapartida de la función de regresión poblacional (FRP). Ya que la FRM se obtiene para una muestra dada como en este caso, lo que una nueva muestra generará otra estimación distinta. Entonces la función de regresión muestral (FRM), que es una estimación de la FRP, viene dada por:

$$
\hat{y}_{i}=\hat{\beta}_{1}+\hat{\beta}_{2} x_{i} \text { Ecuación } 2 .
$$

Permitiendo calcular el valor ajustado $\left(\hat{y}_{i}\right)$ para y cuando $x=x_{i}$. En la FRM y son los estimadores de los parámetros $\beta_{l}$ y $\beta_{2}$. Para cada $x_{\mathrm{i}}$ tenemos un valor observado $\left(y_{i}\right)$ y un valor ajustado $\left(\hat{y}_{i}\right)$. A la diferencia entre $y_{i}$ e $\hat{y}_{i}$ se le denomina residuo. 


$$
\hat{u}_{i}=y_{i}-\hat{y}_{i}=y_{i}-\hat{\beta}_{1}-\hat{\beta}_{2} x_{i} \text { Ecuación } 3 .
$$

En otras palabras, el residuo es la diferencia entre el valor muestral $\left(\mathrm{y}_{\mathrm{i}}\right)$ y el valor ajustado de $\left(\hat{y}_{i}\right)$. En este caso sí es posible calcular empíricamente la descomposición para una muestra dada:

$$
y_{i}=\hat{y}_{i}+\hat{u}_{i} \text { Ecuación } 4 .
$$

De lo anterior es posible calcular (y) para cada uno de los municipios estudiados, resumido en la ecuación 2; y anotando que cada estimación será distinta. Teniendo en cuenta que por el contrario, $\beta_{1}$ y $\beta_{2}$ son fijos pero desconocidos.

Regresiones entre desplazamiento y variables de producción campesina.

Observados los resultados a partir de las regresiones de las variables, desplazamiento y producción campesina fueron interpretadas con especificidad de la producción de café, cacao, ají y aguacate, respecto de las tendencias productivas de cada una.

\section{Conclusiones}

Estudiada las tendencias y relaciones existentes entre las variables en los municipios objeto de esta investigación se aplicó el modelo, de lo cual se concluye lo siguiente.

\section{Regresión desplazamiento y producción de aguacate}

Existe suficiente evidencia estadística para concluir con un nivel de confianza de 99\% que el modelo es útil, dado una probabilidad de F de 0.0012, es decir, la variable desplazamiento explica la producción de aguacate y es importante en el modelo.

$$
\begin{aligned}
\text { In_aguacate }= & 5,6-0,84 * \text { In desplazamiento } \\
& (0,000)(0,001) \\
& \text { prob }>\mathrm{F}=0,0012
\end{aligned}
$$

De lo anterior, si el desplazamiento aumenta en $1 \%$ la producción de aguacate desciende en $0,84 \%$; de igual manera si no existiera desplazamiento, la producción de aguacate se incrementa en 5,6\%.

\section{Regresión desplazamiento y producción de aji}

Ceteris paribus y con un nivel de significancia del $99 \%$, los resultados arrojados indican que por un incremento del desplazamiento en 1\% de la población afectada; la producción campesina de ají, en los municipios de estudio se reducirá en $0,56 \%$ y tendencialmente menor al de la producción de aguacate. 
Igualmente existe evidencia estadística para inferir con un nivel de confianza del $95 \%$ que el modelo es útil dado una probabilidad de F de 0.000 , es decir; la variable desplazamiento explica la producción de ají en el modelo.

$$
\begin{gathered}
\text { In_aji }=0,50-0,56 * \text { In desplazamiento } \\
(0,055)(0,000) \\
\text { prob }>\mathrm{F}=0,000
\end{gathered}
$$

\section{Regresión desplazamiento y producción de cacao}

Para este caso, los resultados enuncian que por un incremento del desplazamiento en $1 \%$ de la población afectada; la producción campesina de cacao, en Mesetas, Vista Hermosa, San Juanito, La Uribe y La Macarena se reduce en 0,56\%, lo anterior con un nivel de significancia de 99 por ciento y ceteris paribus.

Anotando que los resultados estadísticos del modelo son útiles, asumiendo una probabilidad de $\mathrm{F}$ de 0.001 , e infiriendo que la variable desplazamiento explica la producción de cacao en el modelo y de la misma forma si no existiera desplazamiento, la producción de cacao se incrementa en $4,4 \%$.

$$
\begin{gathered}
\text { In_cacao }=4,4-0,56 * \text { In desplazamiento } \\
(0,000)(0,000) \\
\text { prob }>F=0,001
\end{gathered}
$$

\section{Regresión desplazamiento y producción de café}

Para el caso de la oferta familiar campesina de café, también existe suficiente evidencia estadística para concluir que el modelo es ventajoso dado una probabilidad de F de 0.0100; es decir, la variable desplazamiento explica la producción de aguacate y es importante en el modelo. Los resultados exponen entonces que por un incremento del desplazamiento en $1 \%$ de la población afectada; la producción campesina de café se reduce en $0,65 \%$ en los municipios de estudio; lo anterior con un nivel de significancia de $95 \%$ y ceteris paribus.

$$
\begin{gathered}
\text { In_café }=4,31-0,65 * \text { In desplazamiento } \\
(0,000)(0,000) \\
\text { prob }>F=0,001
\end{gathered}
$$

Es así, que en términos generales se puede inferir que el conflicto armado ha impactado negativamente en la oferta productiva campesina de aguacate, ají, cacao y café en el período 1991- 2014 en los municipios de Mesetas, Vistahermosa, San Juan de Arama, La Uribe y La Macarena; lo que en consecuencia ha generado pérdida en el crecimiento económico de las familias campesinas, debilitando el su crecimiento 
económico. La producción de aguacate fue la más afectada y la producción de ají la que menor impacto negativo generó.

Así mismo, en general se derivan las siguientes conclusiones:

Se analizó el impacto económico de la violencia armada sobre la producción campesina en los municipios de Mesetas, La Uribe, San Juan de Arama, Vista Hermosa y La Macarena; desde el 1991 hasta 2014, período en el cual; se encuentra como referente histórico el proceso de diálogos de paz del gobierno Pastrana Borrero (1998-2002) y basados como referente en la teoría neoclásica de la economía campesina y teoría sociológica liberal del conflicto, teniendo en cuenta que la primera esboza una forma de agricultura familiar campesina de tipo excedentario, característica productiva de la zona y la segunda afirma que el conflicto armado no es causado primordialmente por confrontaciones de clase social, sino que por el contrario, esta también se da por choques de grupo, es decir y para el caso del conflicto colombiano campesinos contra campesinos, terratenientes contra terratenientes, familias contra familias, etc.

Adicionalmente; desde los aspectos metodológicos los supuestos económicos denotan que los productos (aguacate, ají, cacao y café) son cultivados y cosechados en los cinco municipios de estudio sin excepción, perteneciendo estos, de forma cultural, a sistemas de policultivos familiares y no monocultivos, las áreas sembradas y cosechadas son pequeñas $(2 \mathrm{Ha}-20 \mathrm{Ha}$ ), y en la producción se involucra la mayor parte de la familia; lo cual se estableció a través de visitas de campo.

Por otro lado, la evidencia resalta que el período comprendido entre el $2000 \mathrm{y}$ 2010 prácticamente es improductivo y la tendencia de decrecimiento es contundente hasta el punto de no generar producción para algunos casos; posterior a este período se evidencia una recuperación importante en las ofertas productivas, casi comparable a la producción de los años noventa, sobre todo a la de antes del inicio de la zona de distensión.

También es importante resaltar que los habitantes de los municipios, objeto de estudio, han indicado que no solamente la contraofensiva paramilitar afectó el crecimiento migratorio de estos territorios, sino que también la contraofensiva de las fuerzas del Estado provocó afectaciones en la población civil, entre otros, con falsos positivos. Porque han sido una constante desequilibradora en la población de estos municipios del sur del Meta.

Teniendo en cuenta que la lucha contra la insurgencia colombiana ha dejado a la población en medio de las hostilidades y la sospecha, por cuanto el campesino puede ser confundido en muchos casos como guerrillero o auxiliador de este ejército irregular y por lo tanto blanco de los ejércitos paramilitares y sujetos a falsos positivos, que son en realidad, "ejecuciones extrajudiciales". 
Sin embargo, este análisis es una línea de base que permitió establecer un derrotero en la comprensión de la economía campesina y logró delimitar sus alcances teóricos y prácticos, sobre todo en relación con la confusión tácita entre este modelo de producción y lo pertinente a la economía agropecuaria (no tienen la misma lógica), lo anterior teniendo en cuenta que la economía campesina se caracteriza porque el trabajo es desarrollado por la familia (padres e hijos) a través de un modelo de policultivo pecuario, agrícola o mixto y en áreas pequeñas (entre una a diez ha), su lógica primordial es de autoconsumo, aunque con resultados excedentarios en algunos casos (motivo de investigación), mientras que en la economía agropecuaria el trabajo suele ser desarrollado por un solo individuo (empresario, pequeño, mediano o gran productor), que paga jornales o salarios a individuos en los períodos de producción según sea el caso a través de un modelo de monocultivo y en áreas más extensas mayores a 10 hectáreas, su producción es ofertada 100\% al mercado de alimentos por lo que su objetivo económico es la rentabilidad.

Por lo que en consecuencia se concluye que la economía campesina y la economía agropecuaria de forma agregada aportarían al producto interno agropecuario de un país y que el conflicto armado con sus categorías (desplazamiento, masacres, homicidios y secuestros) en la zona ha generado grandes pérdidas económicas y la disminución de la población rural productivamente activa.

No obstante, es necesario aclarar que el modelo, que es lineal simple, y que buscó correlacionar las variables analizadas en este documento, necesariamente tendrá que incorporar otras variables explicativas (ejemplo, crédito, titulación de tierras, precios, cultivos ilícitos, entre otros), para establecer una comprensión más profunda de la problemática de la oferta agrícola campesina; reconociendo que los resultados son un avance importante en busca de tal objetivo.

\section{Referencias}

Cantú, P. (2014). Derecho a la alimentación, soberanía alimentaria y sustentabilidad. Sustentabilidad ecológica. Ciencia UANL, 17(68), 29-34.

CELAC. (2013). I Reunión de Altos Funcionarios sobre Agricultura Familiar de la CELAC. Declaración final. Brasilia.

Dahrendorf, R. (1962). Industrie-und betriebssoziologie, vol. 103. Walter de Gruyter.

Evaluaciones Municipales Agropecuarias. (2014). Ministerio de Agricultura y Desarrollo Rural. Recuperado en http://www.agronet.gov.co/estadistica/Paginas/ default.aspx

García, G. (2008). La teoría del conflicto. Un marco teórico necesario. Prolegómenos Derechos y Valores, 11(22), 29-43. 
Nakajima, C. (1969). Subsistence and commercial family farms: some theoretical models of subjective equilibrium. Subsistence Agriculture and Economic Development, 165, 185.

Pacheco, C., Vidales, O. (2012). Caracterización social, productiva y cultural de la familia campesina en el corregimiento 3 de la ciudad de Villavicencio. (Tesis de grado de maestría). Universidad Cooperativa de Colombia.

Schejtman, A. (2008). Alcances sobre la agricultura familiar en América Latina. En: Diálogo rural iberoamericano: Crisis alimentaria y territorios rurales (San Salvador, 16 de septiembre).

Singh, I., Squire, L., \& Strauss, J. (1986). Agricultural household models: Extensions, applications and policy. The World Bank. 